\title{
Disorders of Sex Development
}

\author{
Kun Suk Kim, Jongwon Kim \\ Department of Urology, University of Ulsan College of Medicine, Seoul, Korea
}

The birth of a new baby is one of the most dramatic events in a family, and the first question is usually "is it a boy or a girl?" The newborn infant with ambiguous external genitalia often comes as a surprise for the doctors as well as the parents and is sometimes described as an endocrine emergency situation presenting a problem of sex assignment. The nomenclature such as 'intersex', 'hermaphrodite', and 'pseudohermaphrodite' is out of date as well as confusing, and many urologists are concerned that these confusing terms could be perceived to be pejorative by some affected families. In response to concerns regarding outdated and controversial terms, the Chicago Consensus held in 2005 recommended new terminology based on the umbrella term disorders of sex differentiation (DSDs). The term DSD has a comprehensive definition including any problem noted at birth in which the genitalia are atypical in relation to the chromosomes or gonads. The karyotype is used as a prefix defining the classification of DSD. DSDs are rare and complex. The optimal management of patients with DSD must be individualized and multidisciplinary, considering all aspects, including psychological care and full disclosure of alternatives relating to surgery type and timing. Although further studies are necessary to confirm guidelines and recommendations fitting for the individual patients with DSD, this article is an attempt to provide a balanced perspective for new taxonomy, clinical evaluation, and medical, surgical, and psychological management of DSD.

\section{Key Words: Genitalia; Sex differentiation disorders}

This is an Open Access article distributed under the terms of the Creative Commons Attribution Non-Commercial License (http://creativecommons. org/licenses/by-nc/3. 0) which permits unrestricted non-commercial use, distribution, and reproduction in any medium, provided the original work is properly cited.

\section{Article History: \\ received 28 October, 2011 \\ accepted 28 November, 2011}

\author{
Corresponding Author: \\ Kun Suk Kim \\ Department of Urology, Asan Medical \\ Center, University of Ulsan College of \\ Medicine, 88, Olympic-ro 43-gil, \\ Songpa-gu, Seoul 138-736, Korea \\ TEL: +82-2-3010-3736 \\ FAX: +82-2-477-8928 \\ E-mail: kskim2@amc.seoul.kr
}

\section{INTRODUCTION}

The newborn infant with ambiguous external genitalia presents a problem of sex assignment and is frequently described as a clinical emergent situation that is distressing to the parents. The word intersex has conventionally been used to refer to the appearance of the external genitalia being at variance with normal development for either sex; however, this term is not favored by many families with ambiguous genitalia [1]. A multidisciplinary meeting of medical and nonmedical experts in Chicago in 2005 (the Chicago Consensus) established revised nomenclature and treatment recommendations in individuals with the newly defined term disorders of sex differentiation (DSDs) replacing terms such as intersex, hermaphroditism, and pseudohermaphroditism [2-4]. DSDs are defined as congenital conditions associated with atypical development of chro- mosomal, gonadal, or anatomical sex [4]. There are limited data on the incidence of DSDs; it is estimated that the overall incidence of DSDs is one in 5,500 [5,6]. Congenital adrenal hyperplasia $(\mathrm{CAH})$ and mixed gonadal dysgenesis are the most common causes of ambiguous genitalia, constituting approximately over $50 \%$ of all cases of genital ambiguity in the newborn period [7]. The incidence of CAH and mixed gonadal dysgenesis worldwide is 1:15,000 and 1:10,000, respectively, but varies considerably among different populations [8,9]. Confirming a cause for DSD and devising a management plan is one of the most challenging clinical conditions for the pediatric urologist. It is important to diagnose DSDs correctly as soon as possible to counsel the parents appropriately. The evaluation and management of DSDs is complex, and a multidisciplinary team approach including a pediatric urologist, a psychiatrist, and a pediatric endocrinologist is required for optimal 
management [4,10-12], with communication with the primary care physician [13]. This article is an attempt to outline pragmatic perspectives in the approach to patients with DSDs.

\section{NOMENCLATURE AND CLASSIFICATION OF DSD}

\section{Dilemma of the preexisting nomenclature}

Advances in understanding the molecular genetic causes of abnormal sexual development and heightened awareness of the ethical and patient-advocacy issues mandated a reexamination of preexisting nomenclature [11]. Terminologies such as intersex, hermaphroditism, and pseudohermaphroditism are controversial; potentially pejorative to patients; and confusing even to urologists [1]. Therefore,

TABLE 1. Revised nomenclature

\begin{tabular}{ll}
\hline \multicolumn{1}{c}{ Previous } & \multicolumn{1}{c}{ Revised } \\
\hline Intersex & $\begin{array}{c}\text { Disorders of sex } \\
\text { development (DSDs) }\end{array}$ \\
$\begin{array}{l}\text { Male pseudohermaphrodite } \\
\text { Undervirilization of an XY male }\end{array}$ & 46, XY DSD \\
Undermasculinization of an XY male & \\
$\begin{array}{l}\text { Female pseudohermaphrodite } \\
\text { Overvirilization of an XX female }\end{array}$ & 46, XX DSD \\
Masculinization of an XX female & Ovotesticular DSD \\
True hermaphrodite & $46, X X$ testicular DSD \\
XX male or XX sex reversal & $46, X Y$ complete gonadal \\
XY sex reversal & dysgenesis \\
\end{tabular}

the term $D S D$ was proposed to indicate congenital conditions with atypical development of chromosomal, gonadal, or anatomic sex. A classification is proposed in which DSDs associated with sex chromosome abnormalities (sex chromosome DSD) were separated from DSDs with a normal chromosome complement (46,XX DSD and 46,XY DSD). The stigmatizing term intersex has thus been replaced by a more general and descriptive term, DSD.

\section{New classification based on Chicago consensus}

Table 1 summarizes the new taxonomy and Table 2 shows the application of the new nomenclatures in clinical situations. Although DSD may be useful as a more global term, these general subcategories seem too nonspecific and less useful to specific clinical situations. Adding diagnostic specificity to the comprehensive DSD definition utilizes knowledge of the karyotype, which is based on recognizing the central role of karyotype analysis in the investigation of DSDs. Subsequently, the confusing mythological term pseudohermaphroditism is replaced. The original summary publications of the Chicago Consensus have not provided precise classifications of the DSDs; therefore, inconsistency exists between the DSD classifications used by each investigator. Further clinical classification based on a primary genetic defect is preferred when available because these could more clearly predict disease-specific outcomes. Although there are potential criticisms to the new nomenclature, the DSD terminology has been generally accepted and is now popularly used in the literature. This term $D S D$ is seen in conferences, in the scientific literature, and even in text books of endocrinology. For exam-

TABLE 2. DSD classification proposed by the Chicago consensus

\begin{tabular}{|c|c|c|}
\hline Sex chromosome DSD & 46,XY DSD & $46, \mathrm{XX}$ DSD \\
\hline 45,X (Turner syndrome and variants) & $\begin{array}{l}\text { Disorders of gonadal (testicular) } \\
\text { development }\end{array}$ & Disorders of gonadal (ovarian) development \\
\hline $\begin{array}{l}\text { 47,XXY (Klinefelter syndrome } \\
\text { andvariants) }\end{array}$ & $\begin{array}{l}\text { Complete gonadal dysgenesis (Swyer } \\
\text { syndrome) }\end{array}$ & Ovotesticular DSD \\
\hline $\begin{array}{l}45, \mathrm{X} / 46, \mathrm{XY} \text { (mixed gonadaldysgenesis, } \\
\text { ovotesticular DSD) }\end{array}$ & Partial gonadal dysgenesis & Testicular DSD (SRY+, dup SOX9) \\
\hline \multirow{9}{*}{$\begin{array}{l}46, \mathrm{XX} / 46, \mathrm{XY} \text { (chimeric,ovotesticular } \\
\text { DSD) }\end{array}$} & Gonadal regression & Gonadal dysgenesis \\
\hline & Ovotesticular DSD & \\
\hline & Disorders in androgen synthesis or action & Androgen excess \\
\hline & $\begin{array}{l}\text { Androgen biosynthesis defect } \\
\text { (17-hydroxysteroid dehydrogenase } \\
\text { deficiency, } 5 \alpha \text {-reductasedeficiency) }\end{array}$ & Fetal (21- or 11-hydroxylase deficiency) \\
\hline & Defect in androgen action (CAIS, PAIS) & Fetoplacental (aromatase deficiency, \\
\hline & LH receptor defects (Leydig & POR) \\
\hline & cellhypoplasia) & Maternal (luteoma, exogenous) \\
\hline & $\begin{array}{l}\text { Disorders of AMH and AMH receptor } \\
\text { (persistent müllerian duct syndrome) }\end{array}$ & \\
\hline & $\begin{array}{l}\text { Other (severe hypospadias, } \\
\text { cloacalextrophy) }\end{array}$ & Other (cloacalextrophy, MURCS) \\
\hline
\end{tabular}

DSD, disorder of sex development; CAIS, complete androgen insensitivity syndrome; PAIS, partial androgen insensitivity syndrome; LH, luteinizing hormone; AMH, anti-müllerian hormone; POR, cytochrome P450 oxidoreductase; MURCS, müllerian duct aplasia; renal aplasia, and cervicothoracic somite dysplasia. 

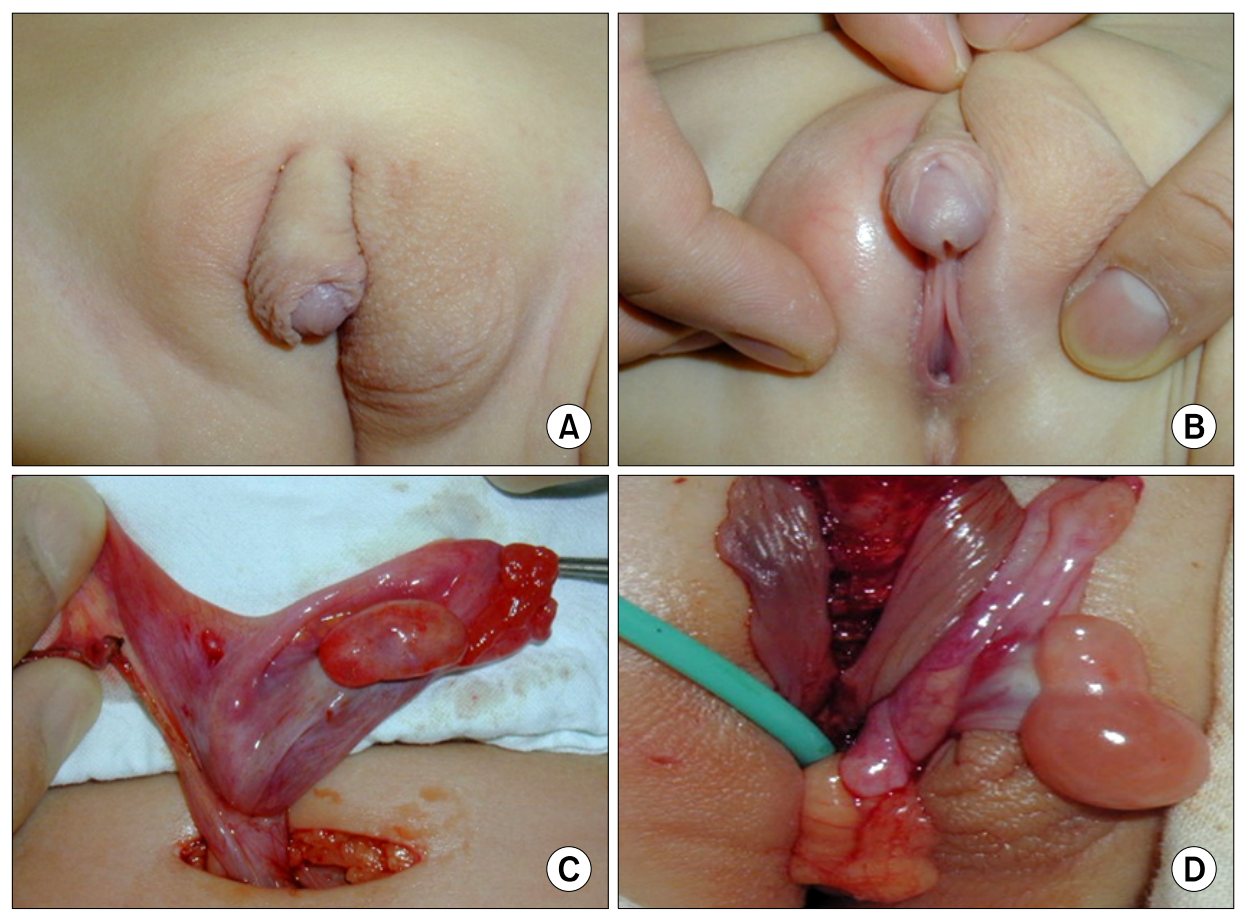

FiG. 1. Medical photographs of patients suggestive of $46, \mathrm{XX}$ disorders of sex differentiation (DSD) (ovotesticular DSD). Asymmetric labioscrotal fold and perineal-type hypospadias were detected through the physical examination. After exploration, the right gonad was determined as an ovary and the left gonad as ovotestis.

ple, the International Society for Hypospadias and Intersex Disorders titled its World Congress "Hypospadias and Disorders of Sex Development."

\section{CLINICAL EVALUATION OF DSD}

The birth of a child with ambiguous external genitalia is highly distressing to families. The first question parents ask about their newborn is whether it is a boy or a girl. The birth of a newborn with ambiguous genitalia comes as a surprise for the parents and doctors alike. Although some researchers report that $60 \%$ of affected children are diagnosed prenatally, many parents are faced with the situation at birth [14]. Healthcare professionals involved in the care of a child with DSD should emphasize to families that a child with DSD has the potential to become a well-adjusted, functional member of society [15].

\section{History}

An initial approach begins with a complete family and prenatal history taking $[4,12]$. A detailed history from the parents is needed that is especially focused on the following: ambiguity, hirsutism, precocious puberty, amenorrhea, infertility, unexplained sudden infant death, or consanguinity. Additionally, maternal exposure to hormones including exogenous hormones used in assisted reproductive techniques and the maternal use of oral contraceptives during pregnancy must be assessed [16-21]. Prenatal androgen exposure is clearly associated with psychosexual development [16,17].

\section{Physical examination}

History taking should be combined with a general physical examination with special attention to the genital anatomy $[4,12]$. Any abnormal virilized or cushingoid appearance of the mother should be checked. It is important to examine the groin and scrotal or labial folds to determine the presence of palpable gonads. For differential diagnosis and treatment purposes, the presence of one or two gonads is an important finding. A palpable gonad is highly suggestive of a testis or rarely an ovotestis (Fig. 1), because the ovaries and streak gonad do not descend. An abnormal phallic size should be noted by width and stretched length measurements. Historically considered, phallus size was considered first in the 1960s when any child with a stretched penile length $<2.5 \mathrm{~cm}$ was likely to be assigned as female regardless of the underlying diagnosis [22]. Through a rectal exam, we can confirm the presence of a uterus and cervix. Physical examination should be done in a warm room and the patient should be placed supine in the frog leg position. It is important to note the size, location, and texture of both gonads, if palpable. The undescended testis could be located in the inguinalcanal, the superficial inguinal pouch, at the upper scrotum, or rarely in the femoral, perineal, or contralateral scrotal regions. All examinations should be done in the presence of the parents, who should be informed exactly what will be done and why. Medical photography requires sensitivity and consent [23].

\section{Criteria of physical findings for DSD evaluation}

Criteria of physical findings suggestive of DSD include: 1) overt genital ambiguity (e.g., cloacal extrophy); 2) apparent female genitalia with an enlarged clitoris and posterior labial fusion (e.g., CAH); 3) apparent male genitalia with bilateral undescended testes, hypospadias, or micropenis; and 4) discordance between genital appearance and a pre- 
natal karyotype [4]. Most DSDs are diagnosed in the neonatal period. Later presentations in older children often include: 1) previously unrecognized genital ambiguity, 2) inguinal hernia in a girl (e.g., complete androgen insensitivity), 3) delayed or incomplete puberty, 4) primary amenorrhea or virilization in a girl, 5) breast development in a boy, and 6) gross or cyclic hematuria in a boy [4]. Given the spectrum of findings and diagnoses, no specific single protocol could be used in the evaluation of DSD patients.

\section{Laboratory tests}

The first-line testing in newborns includes karyotyping with X- and Y-specific probe detection to determine the chromosomal sex; imaging (abdominopelvic ultrasound and retrograde genitogram); serum measurements of 17-hydroxyprogesterone, testosterone, gonadotropins, anti-müllerian hormone, and serum electrolytes to rule out salt-wasting $\mathrm{CAH}$; and urinalysis $[4,12]$. Now many countries screen newborns for CAH by use of filter-paper blood spot 17-hydroxyprogesterone measurements [24]. The testosterone level can help to determine whether the DSD is due to a lack of androgen or cortisone synthesis or rather due to a receptor defect. Once the karyotype is determined, serum measurements will assist in narrowing the differential diagnosis. For example, if the 17-hydroxyprogesterone level is elevated, a diagnosis of $\mathrm{CAH}$ can be made. Determining the levels of 11-deoxycortisol and deoxycorticosterone will help to make a differential diagnosis between 21-hydroxylase and 11 $\beta$-hydroxylase deficiencies. If the levels are elevated, a diagnosis of 11 $\beta$-hydroxylase deficiency could be made, whereas low levels confirm 21-hydroxylase deficiency.

\section{Imaging test}

Noninvasive and inexpensive ultrasound could be the first radiologic examination performed. Abdominopelvic ultrasoundis used for the evaluation of female internal organs and to rule out possible adrenal anomalies. Although it has limited accuracy in detecting intra-abdominal testes, ultrasound can detect gonads in the inguinal region and can identify müllerian anatomy. Retrograde genitogram is performed for the anatomical outlining of the urogenital sinus and for localizing the position and entry of the urethra and vagina into the sinus.

\section{Hormonal stimulation test}

In certain circumstances, additional testing such as human chorionic gonadotropin and adrenocorticotropin stimulation tests to assess testicular and adrenal functions, respectively, are needed. Despite considerable progress in the genetic basis of human sexual development, a specific molecular diagnosis is identified in only $20 \%$ of cases of DSDs [25]. Markedly virilized 46,XX DSDs have CAH; 50\% of undervirilized 46,XY DSDs receive a definitive diagnosis $[26,27]$. Although some gene analyses could be performed in clinical service laboratories, gene testing is not routinely performed in children with DSDs for reasons of cost, in- surance, and quality controls [28].

\section{Diagnostic laparotomy or laparoscopy}

In rare cases in which a definite diagnosis cannot be determined and in infants with intra-abdominal or nonpalpable testes in whom DSDs are considered, open or laparoscopic exploration with biopsy of the gonads could become necessary [29]. In some cases, the differential diagnosis of DSD depends on the interpretation of the histologic features of the gonads [30,31]. Infants with intra-abdominal or nonpalpable testes in whom the precise diagnosis is unavailable with karyotyping and serum study will require an open or laparoscopic exploration with bilateral deep longitudinal gonadal biopsies for histologic evaluation, which will determine the presence of ovotestes, streak gonads, or dysgenetic testes, thereby confirming the diagnosis.

\section{GENDER ASSIGNMENT}

\section{Influencing factors}

Initial gender uncertainty is distressful news for families. Thereby, gender assignment in a newborn with ambiguous genitalia is regarded as a medical emergency, and surgical intervention to match the gender as soon as possible aftermedical stabilization is recommended. Influencing factors to consider when discussing gender assignment include diagnosis, genital appearance, fertility potential, therapeutic/surgical options, and familial views or circumstances relating to cultural biases $[4,32]$.

\section{Gender assignment according to specific diagnosis}

When a specific diagnosis can be made, recommendations for gender assignment can be based upon outcome data. The Chicago Consensus statement did not include specific gender assignment recommendations for all diagnoses, but some consensus participants have provided more specific recommendations. For 46,XX CAH, $90 \%$ of individuals raised as females maintain an assigned female gender identity and do not feel gender dysphoric [33]. Therefore, there is agreement among healthcare professionals to raise these patients as females [12,34]. All patients with 46,XY complete androgen insensitivity syndrome (CAIS), who are assigned female sex in infancy identify as females and there is agreement to raise these patients as females [32,35]. More than $60 \%$ of $5 \alpha$-reductase-deficient patients assigned female gender in infancy and virilizing at puberty and all assigned males live as males and also half of $17 \beta$-hydroxysteroid dehydrogenase-3 deficiency assigned females in infancy ultimately change their gender role [36]. Therefore, it is recommended to discuss with the families when deciding on gender assignment for patients with $5 \alpha$-reductase deficiency and $17 \beta$-hydroxysteroid dehydrogenase-3 deficiency diagnosed in infancy. For patients with partial androgen insensitivity syndrome, androgen biosynthetic defects, and incomplete gonadal dysgenesis, there is dissatisfaction with assigned genders in $25 \%$ of in- 
dividuals whether raised as a boy or a girl [37]. The decision of sex of rearing in patients with ovotesticular DSDs must take into account the potential for fertility based on the degree of gonadal differentiation and genital development. Factors to consider for mixed gonadal dysgenesis also include prenatal androgen exposure, testicular function, phallic development, and gonadal location [4]. The general recommendations are to raise infants with $46, \mathrm{XX}$ CAH or 46,XY CAIS as females, whereas for infants diagnosed with $5 \alpha$-reductase deficiency or $17 \beta$-hydroxysteroid dehydrogenase-3 deficiency, a male assignment should be considered [38].

\section{SURGICAL MANAGEMENT OF AMBIGUOUS GENITALIA}

\section{The aim of surgery}

Surgery can relieve parental distress and improve attachment between the child with DSD and the family [39-42]. The aim of surgery is to make ambiguous external genitalia compatible with assigned gender, preventing urinary obstruction or infections, preserving sexual and reproductive potentials, and maximizing anatomy to enhance sexual function [12]. Surgical corrections usually concern the gonads and the outer genitalia and often the presence of a urogenital sinus. There is no evidence that prophylactic removal of asymptomatic discordant structures is required. In general, it is recommended that the decision about genital surgery should be made by the parents and, when possible, the patient, under the counseling of the medical team. It is important to inform the parents that a functional outcome is more important than a cosmetic outcome. Patients and parents should not be given unrealistic expectations about penile reconstruction.

\section{The timing of surgery}

In the opinion of some experts, genital surgery in infancy that makes an appearance consistent with the gender of rearing is of significant psychological support to the family. However, others suggest that appearance-altering operation is not urgent and that it is more appropriate to delay surgery until a patient is old enough to be informed fully and to provide consent. Although there are still controversies about the optimal timing of the surgery, the American Academy of Pediatrics guidelines on the timing of genital surgery recommend genitoplasty between 2 and 6 months of age [43] and many pediatric urologists also recommend early feminizing genitoplasty $[12,44]$. Also, some studies have demonstrated satisfactory outcomes from early surgery $[12,37,44,45]$. The rationale for early reconstruction is based on the aforementioned guidelines on the timing of genital surgery from the American Academy of Pediatrics, the beneficial effects of estrogen in early time, preventing potentially harmful effects from the communication between the urinary tract and peritoneum through the fallopian tubes, minimizing family concerns, and alleviating the risks of stigmatization and gender-identity con- fusion $[39,43,44]$.

\section{Surgical procedures}

Feminizing genitoplasty for the infants who are to be raised as females includes 1) removing the corporal bodies, 2) creating a normal-looking introitus and labia minora and majora, and 3) vaginoplasty to provide an adequate opening. Masculine reconstruction may include 1) orchiopexy, 2) hypospadias repair, and 3) removal of retained müllerian duct structures.

\section{Clitoroplasty}

Clitoroplasty should be considered only in cases of severe virilization and should be performed combined with repair of the common urogenital sinus. Until the 1960s, the principal surgical procedure for clitoromegaly was clitoridectomy. Amputation of the clitoris leaves a female-appearing perineum but orgasmic function and erectile sensation may be disturbed. Total removal of the clitoris is contraindicated, and when clitoral reduction is performed, sparing the neurovascular bundle is important for the preservations of intact orgasmic function and erectile sensation $[46,47]$.

\section{Vaginoplasty}

Some prefer to correct the external genitalia in a single-stage procedure in the newborn period to take advantage of all native genital tissue and to avoid scarring $[40,48,49]$. Others advocate postponement with the vaginal reconstruction until puberty when vaginal dilatations are more feasible to prevent vaginal stenosis [50]. Because the risk of vaginal stenosis is high following vaginoplasty before puberty, delayed vaginoplasty could be considered if the urinary drainage is adequate. Several options such as self-dilatation, skin substitution, and bowel vaginoplasty have specific advantages and disadvantages; thereby, no one technique could be invariably applied. To prevent stenosis, vaginal dilatation can begin 2 weeks after the operation. However, vaginal dilatation in early childhood is prohibited.

\section{Labioplasty}

Labioplasty is performed at the time of the vaginoplasty and gives the external genitalia a normal female appearance [51,52]. During clitoroplasty, the remnant skin from the clitoris shaft could be used to make the labia minora and majora [53].

\section{Phalloplasty}

Currently, there is no tissue available to increase the size of an underdeveloped phallus in humans. In patients with DSD associated with hypospadias requiring phalloplasty, the complexity of this procedure must be discussed during the initial counseling and standard surgical repair including chordee correction, urethral reconstruction, and judicious testosterone supplementation is recommended [54]. 


\section{Gonadectomy}

Although there is controversy regarding the timing of gonadectomy, it is commonly recommended soon after diagnosis because estrogen-replacement therapy could be started $[4,55]$. The advantages of late gonadectomy include breast development and avoidance of poor adolescent compliance with estrogen-replacement therapy. Germ cell malignancy only occurs in patients with DSD who have Y-chromosomal material (GBY region). Testes in patients with 46,XY gonadal dysgenesis who are raised as a female should be removed to prevent testicular malignancy [55]. In patients with androgen biosynthetic defects raised female, gonadectomy should be performed before puberty. A scrotal testis in patients with gonadal dysgenesis is at risk for malignancy. Thereby, current recommendations are to perform testicular biopsy at puberty, seeking carcinoma in situ or undifferentiated intratubular germ cell neoplasia, which are premalignant lesions [56]. If positive, the option is sperm banking before treatment with local low-dose radiotherapy [56]. In female patients with ovotesticular DSD, the tumor risk is low $(<5 \%)$, but removal of the testicular component in early life is recommended to preserve fertility potential [57].

\section{STEROID REPLACEMENT}

Hypogonadism is common in patients with dysgenetic gonads, defects in sex-steroid biosynthesis, and resistance to androgens. Hormone-replacement therapy is often required to induce and sustain puberty, induce secondary sexual characteristics and pubertal growth spurt, optimize bone mineral accumulation, and for psychosocial maturation in patients with DSD [58]. Boys with hypogonadism require intramuscular injections of either testosterone cypionate or ethanate for pubertal induction [59]. Other testosterone preparations such as gels and patches are available [60-62]. In girls with hypogonadism, estrogen supplementation to induce secondary sexual changes and menstruations is required. Estrogen can be given orally, by injection, orpatch [59]. A progestin is usually added after breakthrough bleeding develops or within 1 to 2 years of continuous estrogen.

\section{PSYCHOSOCIAL SUPPORT}

Current recommendations emphasize sensitive, supportive interactions with families, and full disclosures of the risks, benefits, and potential outcomes of intervention to allow them to participate as fully as possible in decision making and in the continuing care of their child. Psychosocial care should be an integral part of management to promote positive adaptation. Families and individuals require ongoing counseling by experienced personnel to identify maladaptive coping strategies, deal with challenges such as gender dysphoria and sexual dysfunction as they arise, and facilitate age-appropriate information sharing with their affected child. Other im- portant resources include access to confidential sexual counseling and support groups. Regular follow-up from infancy to adulthood of sexual, psychological, and social parameters is needed to provide a favorable long-term outcome for patients with DSD.

\section{CONCLUSIONS}

DSD with ambiguous genitalia is a rare disorder requiring prompt investigation and early gender assignment that is logically based on a sound knowledge of normal sex determination and differentiation. Despite the significant advances that have been achieved, much remains to be clarified in terms of the accurate evaluation and optimal management of patients with DSD. The complexity of the problem requires a multidisciplinary team working together, including a pediatric urologist, pediatric endocrinologist, psychiatrist, and social workers for the proper management of patients with DSD. Affected patients and the parents should be provided with full information to make an appropriate choice for gender assignment. The aims of management in a newborn with DSD should be the provision of a stable gender identity with psychological support to the family, potential sexual function and fertility, and affirmative body image. The surgical correction technique and the timing of the operation need to be individualized according to medical conditions, experience of the surgeon, and the complexity of each case. The general trend is towards early reconstruction with subsequent early and long-term management of the patient. The discussion of the evaluation and management of patients with DSD continues. Future study with further data is essential to suggest enhanced clinical guidelines and recommendations fitting the case of each individual patient.

\section{CONFLICTS OF INTEREST}

The authors have nothing to disclose.

\section{REFERENCES}

1. Conn J, Gillam L, Conway GS. Revealing the diagnosis of androgen insensitivity syndrome in adulthood. BMJ 2005;331: 628-30.

2. Hughes IA, Houk C, Ahmed SF, Lee PA; LWPES Consensus Group; ESPE Consensus Group. Consensus statement on management of intersex disorders. Arch Dis Child 2006;91:554-63.

3. Houk CP, Hughes IA, Ahmed SF, Lee PA; Writing Committee for the International Intersex Consensus Conference Participants. Summary of consensus statement on intersex disorders and their management. International Intersex Consensus Conference. Pediatrics 2006;118:753-7.

4. Lee PA, Houk CP, Ahmed SF, Hughes IA; International Consensus Conference on Intersex organized by the Lawson Wilkins Pediatric Endocrine Society and the European Society for Paediatric Endocrinology. Consensus statement on management of intersex disorders. International Consensus Conference on Intersex. Pediatrics 2006;118:e488-500.

5. Blackless M, Charuvastra A, Derryck A, Fausto-Sterling A, Lauzanne K, Lee E. How sexually dimorphic are we? Review and 
synthesis. Am J Hum Biol 2000;12:151-66.

6. Sax L. How common is intersex? A response to Anne Fausto-Sterling. J Sex Res 2002;39:174-8.

7. Thyen U, Lanz K, Holterhus PM, Hiort O. Epidemiology and initial management of ambiguous genitalia at birth in Germany. Horm Res 2006;66:195-203.

8. Pang SY, Wallace MA, Hofman L, Thuline HC, Dorche C, Lyon IC, et al. Worldwide experience in newborn screening for classical congenital adrenal hyperplasia due to 21-hydroxylase deficiency. Pediatrics 1988;81:866-74.

9. Skakkebaek NE. Testicular dysgenesis syndrome. Horm Res 2003;60(Suppl 3):49.

10. Lee PA. A perspective on the approach to the intersex child born with genital ambiguity. J Pediatr Endocrinol Metab 2004;17: 133-40.

11. Frader J, Alderson P, Asch A, Aspinall C, Davis D, Dreger A, et al. Health care professionals and intersex conditions. Arch Pediatr Adolesc Med 2004;158:426-8.

12. Clayton PE, Miller WL, Oberfield SE, Ritzén EM, Sippell WG, Speiser PW. Consensus statement on 21-hydroxylase deficiency from the European Society for Paediatric Endocrinology and the Lawson Wilkins Pediatric Endocrine Society. Horm Res 2002;58: 188-95.

13. American Academy of Pediatrics Council on Children with Disabilities. Care coordination in the medical home: integrating health and related systems of care for children with special health care needs. Pediatrics 2005;116:1238-44.

14. Nihoul-Fékété C. The Isabel Forshall Lecture. Surgical management of the intersex patient: an overview in 2003. J Pediatr Surg 2004;39:144-5.

15. Dreger AD, Chase C, Sousa A, Gruppuso PA, Frader J. Changing the nomenclature/taxonomy for intersex: a scientific and clinical rationale. J Pediatr Endocrinol Metab 2005;18:729-33.

16. Cohen-Bendahan CC, van de Beek C, Berenbaum SA. Prenatal sex hormone effects on child and adult sex-typed behavior: methods and findings. Neurosci Biobehav Rev 2005;29:353-84.

17. Meyer-Bahlburg HF. Gender and sexuality in classic congenital adrenal hyperplasia. Endocrinol Metab Clin North Am 2001;30: 155-71.

18. Goy RW, Bercovitch FB, McBrair MC. Behavioral masculinization is independent of genital masculinization in prenatally androgenized female rhesus macaques. Horm Behav 1988;22:55271.

19. Wallen K. Hormonal influences on sexually differentiated behavior in nonhuman primates. Front Neuroendocrinol 2005;26:7-26.

20. Moore CL. The role of maternal stimulation in the development of sexual behavior and its neural basis. Ann N Y Acad Sci 1992; 662:160-77.

21. Wallen K. Nature needs nurture: the interaction of hormonal and social influences on the development of behavioral sex differences in rhesus monkeys. Horm Behav 1996;30:364-78.

22. Donahoe PK, Powell DM, Lee MM. Clinical management of intersex abnormalities. Curr Probl Surg 1991;28:513-79.

23. Creighton S, Alderson J, Brown S, Minto CL. Medical photography: ethics, consent and the intersex patient. BJU Int 2002; 89:67-71.

24. Honour JW, Torresani T. Evaluation of neonatal screening for congenital adrenal hyperplasia. Horm Res 2001;55:206-11.

25. MacLaughlin DT, Donahoe PK. Sex determination and differentiation. N Engl J Med 2004;350:367-78.

26. Ahmed SF, Cheng A, Dovey L, Hawkins JR, Martin H, Rowland $\mathrm{J}$, et al. Phenotypic features, androgen receptor binding, and mu- tational analysis in 278 clinical cases reported as androgen insensitivity syndrome. J Clin Endocrinol Metab 2000;85:658-65.

27. Morel Y, Rey R, Teinturier C, Nicolino M, Michel-Calemard L, Mowszowicz I, et al. Aetiological diagnosis of male sex ambiguity: a collaborative study. Eur J Pediatr 2002;161:49-59.

28. Quillin JM, Jackson-Cook C, Bodurtha J. The link between providers and patients: how laboratories can ensure quality results with genetic testing. Clin Leadersh Manag Rev 2003;17:351-7.

29. Park JG, Cha YB, Kim CI, Kim KS. Impalpable testis: localization and management. Korean J Urol 1990;31:665-70.

30. Kim KR, Kwon Y, Joung JY, Kim KS, Ayala AG, Ro JY. True hermaphroditism and mixed gonadal dysgenesis in young children: a clinicopathologic study of 10 cases. Mod Pathol 2002;15:1013-9.

31. Joung JY, Yoo HW, Kim KR, Kim KS. Critical histopathologic findings for differential diagnosis between true hermaphroditism and mixed gonadal dysgenesis. Korean J Urol 2002;43:877-86.

32. Byne W. Developmental endocrine influences on gender identity: implications for management of disorders of sex development. Mt Sinai J Med 2006;73:950-9.

33. Dessens AB, Slijper FM, Drop SL. Gender dysphoria and gender change in chromosomal females with congenital adrenal hyperplasia. Arch Sex Behav 2005;34:389-97.

34. Diamond DA, Burns JP, Mitchell C, Lamb K, Kartashov AI, Retik AB. Sex assignment for newborns with ambiguous genitalia and exposure to fetal testosterone: attitudes and practices of pediatric urologists. J Pediatr 2006;148:445-9.

35. Mazur T. Gender dysphoria and gender change in androgen insensitivity or micropenis. Arch Sex Behav 2005;34:411-21.

36. Cohen-Kettenis PT. Gender change in 46,XY persons with 5alpha-reductase-2 deficiency and 17beta-hydroxysteroid dehydrogenase-3 deficiency. Arch Sex Behav 2005;34:399-410.

37. Migeon CJ, Wisniewski AB, Gearhart JP, Meyer-Bahlburg HF, Rock JA, Brown TR, et al. Ambiguous genitalia with perineoscrotal hypospadias in 46,XY individuals: long-term medical, surgical, and psychosexual outcome. Pediatrics 2002;110:e31.

38. Mendonca BB, Inacio M, Costa EM, Arnhold IJ, Russell DW, Wilson JD. Male pseudohermaphroditism due to 5 alpha-reductase 2 deficiency: outcome of a Brazilian cohort. Endocrinologist 2003;13:201-4.

39. Crouch NS, Minto CL, Laio LM, Woodhouse CR, Creighton SM. Genital sensation after feminizing genitoplasty for congenital adrenal hyperplasia: a pilot study. BJU Int 2004;93:135-8.

40. Rink RC, Adams MC. Feminizing genitoplasty: state of the art. World J Urol 1998;16:212-8.

41. Farkas A, Chertin B, Hadas-Halpren I. 1-Stage feminizing genitoplasty: 8 years of experience with 49 cases. J Urol 2001;165: 2341-6.

42. Baskin LS. Anatomical studies of the female genitalia: surgical reconstructive implications. J Pediatr Endocrinol Metab 2004; 17:581-7.

43. Timing of elective surgery on the genitalia of male children with particular reference to the risks, benefits, and psychological effects of surgery and anesthesia. American Academy of Pediatrics. Pediatrics 1996;97:590-4.

44. Warne G, Grover S, Hutson J, Sinclair A, Metcalfe S, Northam $\mathrm{F}$, et al. A long-term outcome study of intersex conditions. J Pediatr Endocrinol Metab 2005;18:555-67.

45. Lee PA, Witchel SF. Genital surgery among females with congenital adrenal hyperplasia: changes over the past five decades. J Pediatr Endocrinol Metab 2002;15:1473-7.

46. Kogan SJ, Smey P, Levitt SB. Subtunical total reduction clitoroplasty: a safe modification of existing techniques. J Urol 
1983;130:746-8.

47. Gearhart JP, Burnett A, Owen JH. Measurement of pudendal evoked potentials during feminizing genitoplasty: technique and applications. J Urol 1995;153:486-7.

48. Schnitzer JJ, Donahoe PK. Surgical treatment of congenital adrenal hyperplasia. Endocrinol Metab Clin North Am 2001;30:13754.

49. Gonzalez R, Fernandes ET. Single-stage feminization genitoplasty. J Urol 1990;143:776-8.

50. Snyder HM 3rd, Retik AB, Bauer SB, Colodny AH. Feminizing genitoplasty: a synthesis. J Urol 1983;129:1024-6.

51. Frimberger D, Gearhart JP. Ambiguous genitalia and intersex. Urol Int 2005;75:291-7.

52. Kwon JB, Yoo ES, Chung SK. Surgical correction of intersex with feminizing genitoplasty. Korean J Urol 2004;45:1028-34.

53. Oesterling JE, Gearhart JP, Jeffs RD. A unified approach to early reconstructive surgery of the child with ambiguous genitalia. $J$ Urol 1987;138:1079-82.

54. Mouriquand PD, Mure PY. Current concepts in hypospadiology. BJU Int 2004;93(Suppl 3):26-34.

55. Rangecroft L; British Association of Paediatric Surgeons Working Party on the Surgical Management of Children Born With Ambiguous Genitalia. Surgical management of ambiguous genitalia. Arch Dis Child 2003;88:799-801.
56. Rørth M, Rajpert-De Meyts E, Andersson L, Dieckmann KP, Fosså SD, Grigor KM, et al. Carcinoma in situ in the testis. Scand J Urol Nephrol Suppl 2000;205:166-86.

57. Ramani P, Yeung CK, Habeebu SS. Testicular intratubular germ cell neoplasia in children and adolescents with intersex. Am J Surg Pathol 1993;17:1124-33.

58. Warne GL, Grover S, Zajac JD. Hormonal therapies for individuals with intersex conditions: protocol for use. Treat Endocrinol 2005;4:19-29.

59. Drobac S, Rubin K, Rogol AD, Rosenfield RL. A workshop on pubertal hormone replacement options in the United States. J Pediatr Endocrinol Metab 2006;19:55-64.

60. Rogol AD. New facets of androgen replacement therapy during childhood and adolescence. Expert Opin Pharmacother 2005;6: 1319-36.

61. Ahmed SF, Tucker P, Mayo A, Wallace AM, Hughes IA. Randomized, crossover comparison study of the short-term effect of oral testosterone undecanoate and intramuscular testosterone depot on linear growth and serum bone alkaline phosphatase. J Pediatr Endocrinol Metab 2004;17:941-50.

62. Mayo A, Macintyre H, Wallace AM, Ahmed SF. Transdermal testosterone application: pharmacokinetics and effects on pubertal status, short-term growth, and bone turnover. J Clin Endocrinol Metab 2004;89:681-7. 